\title{
Jesús y su búsqueda de un lugar heterópico para devenir Viva
}

\author{
Jesús and his search for a heterotopic place to become Viva
}

\author{
Leonor Taiano \\ University of Notre Dame du Lac \\ Itaianoc@nd.edu \\ https://orcid.org/0000-0002-5634-9020
}

\section{Resumen}

Este artículo analiza la película irlandesa-cubana Viva, el estudio parte de la perspectiva que el cabaré constituye un espacio heterotópico que permite que Jesús pueda devenir Viva. También se considera que el encuentro Jesús/Ángel y los elementos económico-sociales que circundan a ambos personajes, centralizándose en el contraste barrio-cabaré y la importancia del segundo como un contra-lugar de la cotidianidad diurna de Jesús, el sitio donde puede explorar y asumir su feminidad sin ser juzgado. Asimismo, se examina la importancia que la parrhesía entre Jesús/Viva y Ángel tiene como elemento trascendental para que ambos puedan conocerse, aceptarse y recuperar el tiempo perdido.

Palabras clave: Viva; película irlandesa-cubana; cabaré; Paddy Breathnach; espacio heterotópico.

\section{Abstract}

This paper analyzes the Irish-Cuban movie entitled Viva. This research takes as its starting point the idea that the cabaret constitutes a heterotopic space that allows Jesus to become Viva. In addition, I examine the encounter between Jesús/Viva and Ángel and the socioeconomic aspects that surround these characters, by paying special attention to the contrast between the neighborhood and the cabaret, by focusing on the importance of the second one as an alternative to the daily ordinariness. The cabaret is the place in which Jesus can assume their feminine side without being judged. Furthermore, this paper examines the importance of the parrhesia between Jesús/Viva and Ángel has as a key element to allow them to know and accept each other and to make up for lost time.

Keywords: Viva; Irish-Cuban movie; cabaret; Paddy Breathnach; heterotopic space. 


\section{Introducción}

Viva (2015) es una película dirigida por el irlandés Paddy Breathnach. El título de la misma proviene del nombre artístico que Jesús, el protagonista, escogió para actuar como vedette-drag queen en un cabaré de La Habana. Travestirse le permitirá crear una realidad alternativa a su vida de pobreza. Además, será su única salida para dejar los trabajos precarios de peluquero y prostituto. Sin embargo, el repentino regreso de su padre, quien estaba en la cárcel por asesinato, constituirá una ruptura con el espacio heterotópico que había encontrado. Padre e hijo se verán obligados a conocerse, aceptarse y respetarse. Finalmente, el encuentro entre los dos permitirá que Jesús pueda devenir verdaderamente Viva ${ }^{1}$.

El presente estudio se centraliza en la función del cabaré como espacio heterotópico y en la importancia del encuentro padre/hijo para que Jesús pueda devenir totalmente Viva. El texto se divide en tres partes. En la primera, menciono las tesis de Yannelys Aparicio y Ángel Esteban sobre la relación entre Viva y Fresa y Chocolate. Esta comparación me permite analizar la manera cómo Viva puede ser considerada una película comprometida. En la segunda parte comparo el ambiente del barrio con el cabaré. Esta comparación me consiente profundizar sobre los conceptos de heterotopía y de devenir. Además, me permite hacer un breve análisis de algunos personajes que forman parte de la cotidianidad del protagonista. En la tercera parte se escudriña sobre la relación de Jesús con su padre.

El planteamiento de este estudio se apoya en la hipótesis de que el cabaré es un lugar heterotópico donde Jesús puede hacer de su cuerpo la agencia y el instrumento para hacer salir a flote su feminidad.

\section{2 ¿Similitudes con Fresa y Chocolate?}

La discriminación a los homosexuales en Cuba ha constituido el leitmotiv de varias películas cubanas y extranjeras ambientadas en Cuba. Conducta impropia (1983), Fresa y Chocolate (1993), Antes de que anochezca (2000), Chamaco (2010), Verde Verde (2012), Vestido de novia (2014), Fátima o el parque de la fraternidad (2012), Casa vieja (2012), La partida (2013), entre otras, muestran las desventuras que cotidianamente vive la comunidad LGBTI en la isla caribeña.

En comparación a las películas apenas mencionadas, los estudios académicos sobre Viva son casi inexistentes. De hecho, la mayor parte de la información sobre este filme proviene de reseñas cinematográficas periodísticas cuyo carácter excesivamente breve y comercial la encasillan a su protagonista como un "troubled drag queen" (Star Observer Magazine, 2016: 44), sin profundizar sobre la multiplicidad del personaje.

\footnotetext{
${ }^{1}$ La película fue dirigida por Paddy Breathnach. El guion fue escrito por Mark O'Halloran, ganador del Evening Standard British Award por el guion de la película Adam \& Paul (2004). La música fue compuesta por Stephen Rennicks ganador del Canadian Screen Award for Best Score por la banda sonora de Room (2016). La dirección de fotografía estuvo bajo la responsabilidad de Cathal Watters, ganador del Winner Best Cinematography IFTA 2016 por las imágenes de Viva. Los actores principales de la película son cubanos: Héctor Medina (Jesús-protagonista), Jorge Perugorría (Ángel- padre), Luis Alberto García (Mama-propietario cabaré).
} 
En el plano académico, el estudio que ha dedicado mayor atención a la película es el de Yannelys Aparicio y Ángel Esteban, quienes, para convertirla en un ejemplar de la producción cinematográfica de los nuevos tiempos cubanos, tratan de establecer estrechas conexiones entre esta y Fresa y Chocolate, dirigida por Tomás Gutiérrez Alea y Juan Carlos Tabío. Los estudiosos afirman que a partir de esta película Paddy Breathnach comenzó a interesarse por el tema de la homosexualidad en Cuba y visitó un club donde actuaban drag Queens. Aunque ya había asistido a este tipo de establecimientos en otros países, al cineasta le llamó la atención ese mundo sumergido, supuestamente clandestino y abierto a extremos de libertad que apenas podía imaginarse en una dictadura tan férrea como la cubana (Aparicio y Esteban, 2017, p. 130).

Según ambos críticos, la relación más interesante entre Fresa y Chocolate y Viva es el capital simbólico que se genera alrededor de las figuras representadas por Jorge Perugorría. En la película de los noventa es el joven homosexual y religioso vinculado al mundo de la literatura y el arte que desea expresarse libremente como revolucionario sin asociarse al modelo de "hombre nuevo" guevariano y que termina abandonando el país porque no cabe dentro del status quo elaborado, fijado y fosilizado por el régimen. En Viva, Perugorría, veinte años más viejo, y con apariencia, en la película, de hombre decrépito, desaseado, bebedor y abandonado desde el punto de vista físico y moral, encarna el personaje de padre de un joven que desea abrirse camino en el mundo del arte y la representación musical, en un establecimiento de drag-Queens (Aparicio y Esteban, 2017, p. 131).

A pesar del interés del irlandés por la galardonada obra cinematográfica y de las relaciones forzadas que ambos críticos ven entre los personajes interpretados por Perugorría, los guiones de Fresa y Chocolate y Viva difieren mucho. El primero, basado en el relato El lobo, el bosque y el hombre nuevo de Senel Paz, pone a la luz elementos sociopolíticos que incluyen la sobrevaloración gubernamental del hombre nuevo, la persecución a los homosexuales y la censura hacia el trabajo de los artistas o intelectuales contrarrevolucionarios durante los primeros años de la dictadura de Fidel Castro. El segundo, escrito por Mark O'Halloran, se centraliza en las cuestiones relacionadas con la pobreza, el jineterismo y el travestismo, hace muy pocas alusiones al machismo revolucionario y no hace ninguna mención sobre las nuevas leyes de tolerancia hacia la diversidad sexual.

Si bien la película no se sumerge en la política cubana, Viva es un filme comprometido que muestra la doble moral de una sociedad que tacha de débiles a los homosexuales, finge no percatarse de los ingresos económicos que genera la prostitución masculina y cierra los ojos ante la discriminación sexual. La película combina elementos sociales con teorías de género, pero lo hace de un modo que la encasilla más dentro de la categoría del cine espectacular que en la del cine intelectual (Elsaesser, 1991, p. 75).

Hablando en sentido deleuzien ${ }^{2}$, en Viva la relación entre el acto de creación y el de resistencia sucede por el refuerzo imagen-sonido que permite mostrar la lucha cotidiana de Jesús y su búsqueda de un lugar heterópico para devenir Viva. La combinación de planos generales de la Habana con planos enteros de los ambientes que el protagonista frecuenta está subordinada a

\footnotetext{
${ }^{2}$ En su conferencia Qu'est-ce que l'acte de création ? Gille Deleuze afirma que todo acto de creación surge a partir de una necesidad. En el caso específico del cineasta-creador este fabrica un bloque de movimientos-duración que encuentra sus límites en el espacio-tiempo. Tener una idea en el campo cinematográfico no encarna generar un concepto, significa transformar los movimientos y sonidos, poniendo en circulación una serie de elementos simultáneamente (Deleuze, 1987). Según Deleuze, el acto de creación no es del orden de la comunicación. La obra de arte no contiene ninguna información. Por el contrario, existe una afinidad fundamental entre esta y el acto de resistencia. El francés usa como ejemplo el cine de Jean-Marie Straub, quien hacía de la disyunción voz-imagen un acto de resistencia contra la repartición de lo profano y lo sacro (Deleuze, 1987).
}

Revista del Laboratorio Iberoamericano para el Estudio

Sociohistórico de las Sexualidades https://doi.org/10.46661/relies.5912 
diálogos, discusiones y canciones, que muestran los estados de ánimo e inquietudes de un individuo que se siente rechazado por su entorno y que ve en el travestismo una vía de liberación.

\section{Del sombrío barrio al refulgente cabaré}

Los diálogos de la película fluyen con facilidad. Las conversaciones son directas, pertinentes y, en muchos casos, agresivas. La mayor parte de ellos se relacionan con las expectativas de Jesús sobre sus conflictos personales, su relación con el padre y sus deseos de asumir su feminidad, pero también cubren otros aspectos como la prostitución, el alcoholismo, alguna leve crítica a la revolución, el machismo, la pobreza y el travestismo. Los temas económico-sociales son generalmente abordados con los personajes del barrio, mientras que las cuestiones relacionadas con la performatividad sexual y la libertad de devenir quien uno desea se tratan en el cabaré.

Las imágenes diurnas de Viva ponen especial énfasis en las condiciones precarias de los proletarios cubanos y en el ambiente degradado en el que estos son abandonados a su suerte. El universo matinal de la película se desarrolla entre el barrio de Jesús, el cuadrilátero de boxeo, su domicilio y la zona turística de La Habana. Las panorámicas de la ciudad vetusta, las ropas descuidadas de los habaneros y su manera de hablar muestran un conjunto de pobres sin dignidad, que ven en la migración o en el "jineterismo" ${ }^{3}$ los únicos modos para escapar del determinismo social (Fusco, 1998, p. 152).

El guion se centraliza en los esfuerzos lícitos e ilícitos de cada personaje del barrio para liberarse de su carga social. Nita evita pagar a Jesús por sus cortes de pelo; Cecilia quiere casarse con el boxeador Javier para irse a vivir a Miami; Javier desea ir a los juegos panamericanos para pedir asilo político y dejar el país definitivamente; Don busca a los "yuma"4 en la zona hotelera para hacer algunos dólares y Jesús combina su oficio de peluquero con la prostitución.

El boxeador Javier, considerado por su gobierno un digno representante del deportista cubano, personifica el fracaso del culto del hombre nuevo. Machista, mujeriego y poco inteligente, usa su fuerza bruta para poder huir hacia los países capitalistas, mientras Jesús, el afeminado, se queda en Cuba y se responsabiliza por la seguridad económica de Cecilia y del hijo que esta está esperando. En la diferencia de proceder entre ambos puede notarse que el segundo tiene un comportamiento menos contrarrevolucionario que el primero, pues nunca se plantea dejar la isla, sabe asumir sus responsabilidades y protege a quien lo necesita. De hecho, la única alusión a la revolución se hace por medio de un diálogo que compara brevemente a los dos personajes:

Ángel: ¿YYa se habrá ido para México?

Jesús: A lo mejor...

Ángel: ¡Javier en los panamericanos! ¡Qué grande es esta revolución!

¿Nunca has pensado en irte?

Jesús: La verdad no... (00:27:04).

Sin embargo, no se debe pensar que Viva cae en la simplificación heterosexual-malo/homosexualbueno. En efecto, otro personaje cuyo exagerado pragmatismo difiere del comportamiento de Jesús es su amigo Don. Este también se dedica a la prostitución masculina, pero es un personaje menos "poético" que el protagonista, pues no siente ningún remordimiento al vender su cuerpo e incluso

3 La voz jineterismo se usa para referirse a las actividades económicas ilegales relacionadas con el turismo, principalmente a la prostitución.

${ }^{4}$ Yuma es una voz coloquial usada en Cuba para referirse a los extranjeros, principalmente a los estadounidenses.

Revista del Laboratorio Iberoamericano para el Estudio Sociohistórico de las Sexualidades https://doi.org/10.46661/relies.5912 
busca estrategias para causar pena en los clientes y obtener mayores beneficios: "A los clientes les encantan las historias tristes. Sentir que te están ayudando. Es como si les quitases un peso de la conciencia" (01.03.10).

En oposición a Jesús, Don es uno que sabe lidiar en el mundo de las "jineteras" 5 y de los "pingueros"6. El personaje muestra los pormenores de la mentalidad "jineterista" cubana que favorece la prostitución. La zona hotelera de La Habana es el área donde él y los "yumas" negocian la penetración, fingiendo toda una forma de cortejo para hacer sentir conquistadores o héroes a sus amantes ocasionales (Sierra Madero, 2013, p. 169).

Aunque Viva no tiene escenas explícitas de sexo, hay dos secuencias que sugieren la prostitución de Jesús con turistas extranjeros. La primera es con un hombre de mediana edad con el que se encuentra en un hotel y le paga por sus servicios. La segunda es con un individuo de edad avanzada, en la cual un primerísimo primer plano de la cara angustiada de Jesús nos da a entender que está siendo maltratado por su cliente.

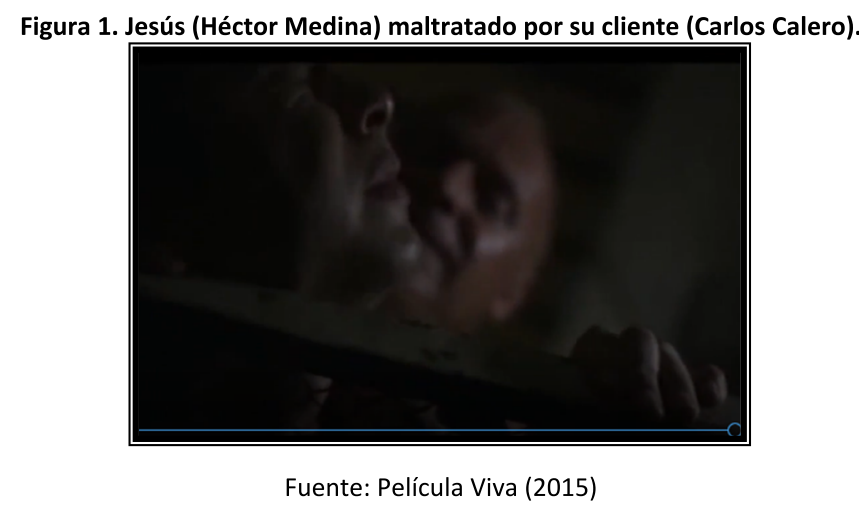

Si bien Jesús se dedica a actividades ilícitas para ganarse el pan, su personaje difiere de todos aquellos que forman el colectivo de su barrio. Es sensible, generoso con lo poco que tiene, sentimental y nostálgico. Estas características predisponen su amor a la música y hacen que encuentre conforto en el ambiente artístico del cabaré. Efectivamente, después de que el cliente lo maltrata, va a refugiarse en este local nocturno donde los transexuales combaten contra la heteronormatividad.

Definiéndolo en modo foucaultniano ${ }^{7}$, podría decirse que en la película el cabaré es presentado como un espacio heterotópico, un lugar-otro donde un joven homosexual puede ser y devenir fuera de la realidad cotidiana y extrema- el personaje trans que completa su ser. Según Foucault las heterotopías son una suerte de "utopías efectivamente realizadas" que existen en contestación, en contraste o en oposición a otros sitios reales que se encuentran en una cultura (Foucault, 2004,

\footnotetext{
${ }^{5}$ Mujeres que se prostituyen con extranjeros.

${ }^{6}$ Hombres que venden su "pinga" o pene a los extranjeros.

${ }^{7}$ Michel Foucault propone seis categorías de heterotopías: a) Las heterotopías de crisis y las de desviación que corresponden a los lugares privilegiados, sagrados o prohibidos que representan un estado o una etapa de crisis personal. En este lugar se incluyen los manicomios, los templos o los hospitales psiquiátricos, b) Las heterotopías que cambian de función y de sentido a través del tiempo. El cementerio pertenecería a este tipo de heterotopías, c) la heterotopía que yuxtapone en un lugar real diferentes sitios extranjeros entre sí, por ejemplo Disney World, d) Las heterotopías relacionadas a las heterocronías, espacios de tiempo y de cultura que son simultáneamente temporáneos y permanentes, por ejemplo los centros vacacionales, e) heterotopías que implican un sistema de abertura y de cierre que las protege y reglamenta. Las heterotopías crean tanto lugares de ilusión como lugares de compensación.
}

Revista del Laboratorio Iberoamericano para el Estudio Sociohistórico de las Sexualidades https://doi.org/10.46661/relies.5912 
p. 12-19). En Viva el cabaré es el contra-lugar de la cotidianidad diurna de Jesús, el sitio donde puede explorar y asumir su feminidad sin ser juzgado. Es el refugio que le permite escapar del prosaísmo que le circunda, por eso pide a Mama, el travesti propietario, que lo deje hacer una audición para convertirse en una drag-queen. En una escena que encuadra las pelucas y los vestidos de las vedettes, Mama le pregunta cuáles son sus razones para querer travestirse. La respuesta de Jesús convence a su interlocutor:

Mama: ¿Por qué quieres hacer esto mijo?

Jesús: No sé bien. Es intenso. Lindo. Quiero algo para mí, Mama. Yo no tengo nada. Ni nadie. Yo no tengo ni familia. También me hace falta el dinero.

Mama: ¿Tú vives de la peluquería?

Jesús: Sí, tal vez tenga que hacer otras cosas...No es que me guste, pero si tengo que hacerlo... (00:13:20).

Es indudable que una de las personas que ayuda a que Jesús vea en el cabaré un refugio es Mama. Esta asume el papel de la consejera del huérfano Jesús y lo induce a la búsqueda de su felicidad. Este personaje es uno de los catalizadores del devenir del protagonista, pues lo encausa para que interprete su personaje con ardor. Gracias a Mama, su madre del espacio heterotópico, Jesús dejará surgir a Viva. De hecho, es en su búsqueda de una vida intensa que Jesús decide devenir Viva, extensión de sí mismo que le proporciona un incentivo para vivir su feminidad con intensidad. Los sucesos traumáticos que ocurren fuera de este espacio bloquean su realización personal, mientras que, en el cabaré, puede reformar la cotidianidad que lo condena. El cabaré le da la capacidad de construir o, mejor dicho, devenir Viva. En este lugar Jesús/Viva altera las connotaciones y significaciones sociales a partir de su performatividad y de su creatividad, pues le permite impugnar las normas de la sociedad y dejar florecer su feminidad.

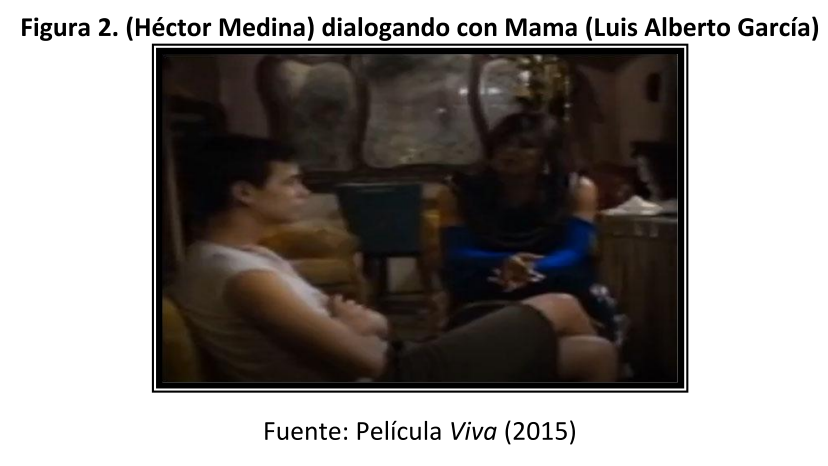

Este florecimiento será progresivo. Iniciará, como se lo señala Mama, con una simple imitación de la feminidad que evolucionará hasta que Jesús logre fusionarse verdaderamente con su personaje. En sus primeras presentaciones, el protagonista está demasiado pendiente de la reacción del público y su espectáculo es anodino, pues no logra transmitir ninguna emoción:

Mama: ¿A ti que te pareció lo que hiciste?

Jesús: Bien.

Mama: Yo no iría tan rápido. Eso fue una mierda. No se trata de tararear la letra de la canción. Jesús: Yo sé...

Mama: No, no lo sabes. No con esas canciones. Tienes que hacerlo con sentimiento. Esas canciones dicen cosas niño. Eso fue una mierda (00:16:00).

A partir de este diálogo, Jesús/Viva comienza a encarnar todas las reacciones necesarias para que su devenir tenga lugar. La vedette se deja llevar por su espontaneidad. Su cara y sus gestos logran 
transmitir reacciones emotivas que van más allá de la simple imitación de lo femenino, son la feminidad propiamente dicha.

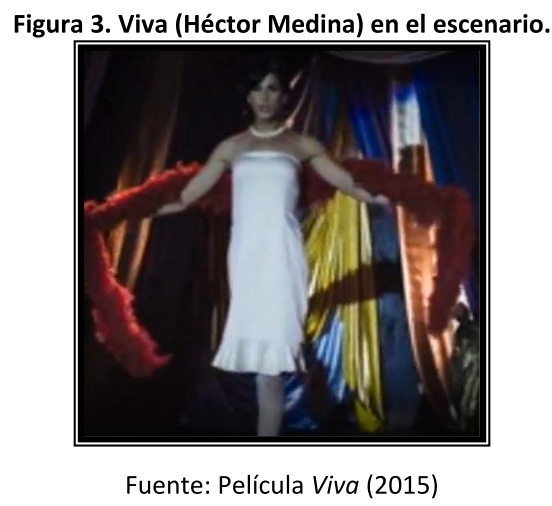

Para Judith Butler, la lucha para rehacer las normas a través de las cuales se experimentan los cuerpos es crucial, no solo para las políticas concernientes a las minusvalías, sino también para los movimientos intersex y transgénero. La alteración de los preceptos que rigen la morfología humana normativa tiene como resultado otorgar una realidad diferencial a los diferentes tipos de humanos. En consecuencia, la filósofa considera que las vidas transgéneros tienen un potencial y un impacto político significativo sobre las reglas que rigen la apariencia de la cualidad "real" del ser humano (Butler, 2006, p. 50-51). Según la estadounidense, la fantasía creada por los drag-queens no es lo opuesto de la realidad; sino lo que esta impide que se realice (Butler, 2006, p. 50-51).

La fantasía es lo que nos permite imaginarnos a nosotros mismos y a otros de manera diferente; es lo que establece lo posible excediendo lo real; la fantasía apunta a otro lugar y, actuando lo incorpora, convierte en familiar ese otro lugar (Butler, 20061, p. 51).

En Viva el cabaré hace posible lo que la realidad hace imposible. Los camerinos donde los travestis se feminizan y el escenario donde se exhiben crean un microcosmos en el que el arte permite combatir contra los estigmas sociales. La película nos hace espectadores de la lucha de los transexuales cubanos, poniendo en claro la esencia de la representación teatral como vía para que las vedettes-transformistas puedan mostrar una verdad más profunda que aquella establecida por la biología y por la heteronormatividad. En Viva, el travestismo es una prueba de coraje y de audacia, una evidencia de que las drag-queens sí saben luchar:

Ángel: ¿Quieres que lo deje andar por ahí enseñando su flojera?

Mama: ¿Para ti esto es flojera? ¿Tú no piensas que yo tengo mi propia lucha? Pues yo sí sé luchar, pa' que sepas (00:59:30).

En Deshacer el género Judith Butler afirma que el cuerpo puede ser la agencia y el instrumento donde "el hacer" y "el ser hecho" se tornan equívocos. Aunque luchemos por sus derechos, el cuerpo no pertenece solamente al individuo, pues tiene invariablemente una dimensión pública (Butler, 2006, p. 41). La filósofa resalta que las personas drag, butch, femme, transgénero y transexuales, no solo nos cuestionan sobre lo que es real y lo que "debe" serlo, sino que también nos muestran cómo pueden ser discutidas las normas que rigen las nociones contemporáneas de realidad, y cómo se constituyen los nuevos modos de realidad. El cuerpo no es un hecho estático y ya realizado, sino un devenir en el que el individuo, al convertirse en algo diferente, excede la norma y hace ver cómo las realidades a las cuales creíamos estar confinados no están escritas en piedra (Butler, 2006, p. 51).

Los transexuales de Viva ponen en cuestión la validez de la heteronormatividad. Su devenir mujeres no radica solamente en su deseo sexual hacia los hombres, sino en su performatividad de la feminidad, que incluye tanto el papel de seductoras como el de protectoras. Ese mundo donde se 
actúa un género diferente del sexo biológico es el universo nocturno de Jesús. Es el espacio en donde tiene la oportunidad de ser lo que él desea, donde puede cantar con euforia y encarnar a Viva gracias a las relaciones intersubjetivas con su público y con las otras vedettes, pues estas permiten la reconfiguración de los códigos heteronormativos.

Uno de los elementos claves de esa reconfiguración radica en la concepción que las vedettes tienen del mundo y de ellas mismas. Jesús aprenderá que a pesar de sus genitales masculinos estas se consideran "125 \% mujeres" (00:19:44) y que muchos de los clientes que van a verlas las consideran verdaderamente femeninas, pues, como dice Cindy "todo es apariencia" (00:19:45).

La afirmación de Cindy es la base de este mundo heterotópico, pues pone fin a la separación entre lo que es "biológico-real" y, en el caso de los drag-queens, "performativo-ficción". En el cabaré la realidad y la apariencia son co-extensivas. Los clientes se sienten atraídos por la auténtica feminidad que representan aquellos hombres "disfrazados" de mujeres. Para Cindy, la frontera entre la apariencia y la realidad no es solamente móvil, es inexistente. Es desde esta perspectiva que Cindy logra la conciliación de su multiplicidad, es como logra crear puntos de conexión entre sus heterogeneidades, entre su ser y su devenir.

Gracias a las personas del cabaré, Jesús entiende que Viva es parte de su multiplicidad, de su rizoma ${ }^{8}$. Jesús y Viva son una unidad, son líneas de segmentaridad del mismo ente, atribuciones del mismo sujeto en base al lugar donde se encuentra. Su representación de Viva en el escenario no es imitación ni semejanza de la feminidad, es el surgimiento de lo que Deleuze y Guattari llaman una línea de fuga, un acto de resistencia y de afirmación (Deleuze \& Guattari, 1978, p. 18).

\section{La confrontación: Del encuentro fallido a la parrhesia}

El espacio heterópico del cabaré es invadido por Ángel, padre de Jesús, quien rechaza las "tendencias" de su hijo golpeándolo públicamente mientras este interpreta la canción ¿Qué te pedí? ${ }^{9}$ Su letra anticipa al espectador que verá la historia de alguien que no logra cubrir las expectativas de la persona amada, insinuando que tendrá lugar un encuentro fallido entre los dos personajes.

Es significativo resaltar que si Ángel pudo irrumpir en el espacio heterotópico de Jesús es porque acababa de salir de otro tipo de heterotopía: la cárcel. Si el cabaré es un contra-lugar para aquellos que no se adaptan a la heteronormatividad, la cárcel es una heterotopía de desviación. Un lugar en el que se encierran a los sujetos considerados legal o mentalmente extraviados. En otras palabras, ambos personajes entran en contacto después de haber conocido espacios dedicados a la alteridad. Aunque padre e hijo son muy diversos, el machismo excesivo del primero y la homosexualidad del segundo convierte a ambos en desadaptados sociales.

\footnotetext{
${ }^{8}$ En Mil mesetas, Gilles Deleuze y Félix Guattari explican que la conciliación entre el ser y el devenir no se hace añadiendo constantemente una dimensión superior al ser, sino, al contrario, de la forma más simple, a fuerza de sobriedad, al nivel de las dimensiones de que dispone, siempre n-1 (Deleuze \& Guattari, 1978, p. 12). Sustraer lo único de la multiciplidad a constituir: escribir a n-1. Este es el tipo de sistema que ambos, basándose en la botánica, llaman rizoma y está sometido a los principios de conexión y de heterogeneidad, al principio de multiciplidad, al principio de ruptura asignificante y al principio de la cartografía y de la calcomanía (1978, p. 12-17)

${ }^{9}$ Se trata de un bolero compuesto por Fernando Mulens López. La canción se hizo célebre por medio de la interpretación de 'La Lupe'. Viva es golpeada mientras canta el coro de la canción: "Hoy me pides tú/las estrellas y el sol no soy un dios/así como soy yo te ofrezco mi amor/no tengo más/pide lo que yo puedo darte/no me importa entregarme/a ti sin condición".
}

Revista del Laboratorio Iberoamericano para el Estudio https://doi.org/10.46661/relies.5912

Sociohistórico de las Sexualidades 


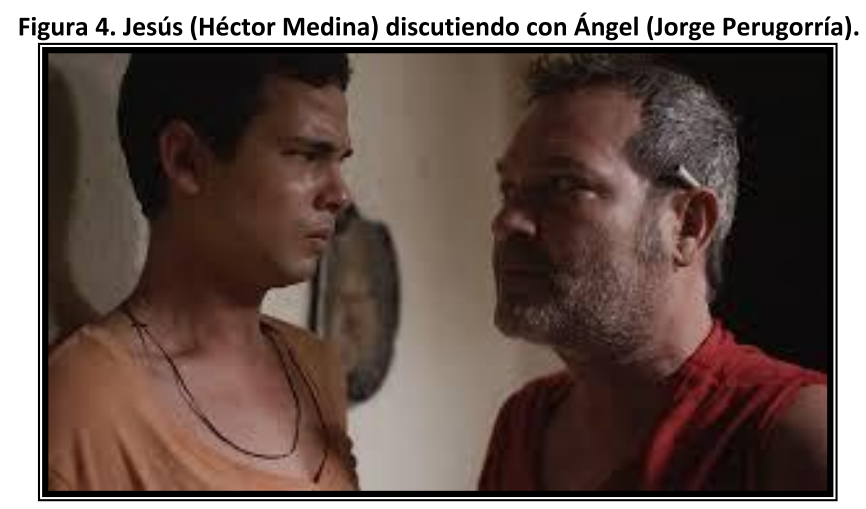

Fuente: Película Viva (2015)

Con la aparición de Ángel, la película nos pone delante del encuentro de dos marginados que han sido expuestos a la soledad. Su aislamiento ha hecho que este ignore muchos particulares de la vida de su hijo. De igual manera, Jesús sabe muy poco sobre su padre. Los vecinos le han referido que era excelente boxeador, que maltrataba a su madre y que mató a un hombre. Su presencia le inspira terror. Entre ambos es difícil superar las tensiones que surgen por los diferentes temperamentos y orientaciones sexuales.

A pesar de que ellos nunca han tenido contacto, pues Jesús tenía solamente tres años cuando Ángel abandonó la casa, el hijo se someterá a la autoridad paterna y dejará su trabajo en el cabaré para encontrar una vía de conciliación. Por su parte, Ángel está convencido de que sus ex-colegas del boxeo le ayudarán a encontrar trabajo y que podrá hacerse cargo de la subsistencia de ambos. Sin embargo, debido a su edad y al descrédito de haber estado en la cárcel le resultará imposible reincorporarse en el mundo laboral. La carestía comienza a hacerse presente y Jesús vuelve a ejercer la prostitución a escondidas de su padre. Debido a los prejuicios patriarcales contra el travestismo, el joven retorna a la existencia que conducía antes de comenzar a trabajar en el cabaré.

Es evidente que para Ángel resulta difícil tener un hijo homosexual. En consecuencia, demoniza a Viva, pues esta representa la puesta en evidencia de la "flojera" de su hijo (00:59:30). Sin embargo, llega un momento en que ambos comienzan a aceptarse recíprocamente y a desarrollar un vínculo afectivo. Aunque el protagonista sabe que su padre lo percibe como alguien vulnerable y poco macho, decide afrontar las diferencias por medio del diálogo:

Jesús: Tú quisieras que yo fuese diferente, ¿iverdad?

No sé. Más macho. Más fuerte.

Ángel: Sería más fácil, ¿no?

Jesús: No sé (01:01:15).

Para conocerse y comprenderse, padre e hijo inician a tener una serie de conversaciones similares a interrogatorios o confesiones. Entre ambos individuos hay un cambio de actitud. Desean liberarse por medio de la verdad, necesitan reforzar los lazos de la consanguinidad por medio de una conversación sincera, libre de ocultamientos.

En El coraje de la verdad, Michel Foucault retoma el concepto griego de parrhesía ${ }^{10}$ para indicar "la práctica de decir la verdad sin esconderla con nada" (Foucault, 2010, p. 19) bajo el riesgo de rechazo

\footnotetext{
${ }^{10}$ La parrhesía, etimológicamente, es la actividad consistente en decirlo todo: pan rhema. Puede emplearse con dos valores. Con un valor peyorativo, la parrhesía consiste en decir todo en el sentido de decir cualquier cosa que pueda ser útil para los propios intereses. En su valor positivo, la palabra parrhesía consiste en decir la verdad sin disimulación ni reserva ni cláusula de estilo ni ornamento retórico que pueda cifrarla o enmascararla.
} 
o la ira del interlocutor. Esta práctica se sitúa en "la prehistoria de algunas parejas célebres: el penitente y su confesor, el enfermo y el psiquiatra, el paciente y el psicoanalista" (Foucault, 2010, p. 26). Al contrario de la retórica, la parrhesía no tiene el objetivo de convencer, tiene el propósito de sincerarse totalmente con el otro, aunque esto cause posteriores problemas.

La parrhesía se convierte en un elemento importante para que Ángel y Jesús puedan conocerse y recuperar el tiempo perdido. Aunque inicialmente ambos temen socavar aún más su relación, saben que sincerarse será la única forma de aclarar las cosas. En cuanto al padre, sus verdades son dos. La primera concierne el plano familiar-sentimental. Confiesa que se siente culpable por no haber cumplido las expectativas de su esposa y por haber fallado como padre. Habla de su adicción al alcohol y de las causas absurdas que lo llevaron a cometer un homicidio. Afirma que sufrió mucho cuando en la cárcel le informaron que su mujer había muerto y que cuando la dejó era porque tenía vergüenza y quería desaparecer para darle una esperanza (01:06:00). La segunda es la confesión de por qué lo dejaron salir de la cárcel: Ángel fue excarcelado porque se encuentra en sus últimos días de vida. Tiene un cáncer pulmonar en estado avanzado.

Ángel: Jesús vine a casa porque...vine a casa porque...me dejaron salir porque estoy jodido... Eso era lo que tenía que decirte.

Jesús: ¿Qué pasa?

Ángel: Pulmones [...] por eso regresé. Se acabó (01:07:23).

Pocos días después de su sinceramiento, la salud de Ángel se agrava y termina en el hospital. Jesús sufre al saber que el único familiar que tiene en este mundo está muriendo. Los médicos le confirman que le quedan semanas. Ángel le pide que lo deje ir a morir en casa, pues desea pasar junto a él sus últimos días. Para poder alimentar y cubrir todas las necesidades del padre, Jesús va a la zona turística y tiene relaciones sexuales con un hombre mayor que lo maltrata. Se siente humillado y en mitad de la noche va a buscar a Mama en el cabaré, le cuenta toda su tragedia y esta le aconseja que se sincere totalmente con su padre: “¿Me dejas darte un consejo mijo? El tiempo que les quede juntos, trata de ser tú. De ser quién eres, o te vas a arrepentir" (01:20:20).

El consejo de Mama, el maltrato del cliente y la sensación dolorosa de estar perdiendo al padre apenas reencontrado le inducen a sincerarse totalmente con su padre. Jesús inicia mencionándolo que regresará al cabaré porque necesitan dinero, pero posteriormente se sincera totalmente y le dice que solamente allí se siente feliz. Es el único sitio en el que se siente en seguridad, donde no debe avergonzarse por ser homosexual y puede ser Viva:

Toda la vida me han hecho sentir culpable por lo que soy. Como si tuviera que sentir pena o disculparme. Flojo o afeminado. No sé. Mira cuando yo entro al escenario, me siento fuerte, sincero. Canto con el alma. Yo nunca antes me había sentido así. Es la música. Es eso. Lo hago por mí (01:23:10).

Después de esta última parrhesía, la trama se acelera y nos lleva al camerino del cabaré, donde Jesús se prepara para interpretar a Viva. Los otros travestis le avisan que su padre se encuentra en el local y temen que lo golpee como hizo anteriormente. Jesús decide salir al escenario y vuelve a interpretar ¿Qué te pedí? de Fernando Mulens López. Esta vez la función termina exitosamente en todos los sentidos. El público aplaude emocionado, Ángel abraza a su hijo y por primera vez lo llama Viva. El decirse todo entre ambos ha llevado a que se acepten como son y que no se pidan más de lo que cada uno puede dar. 


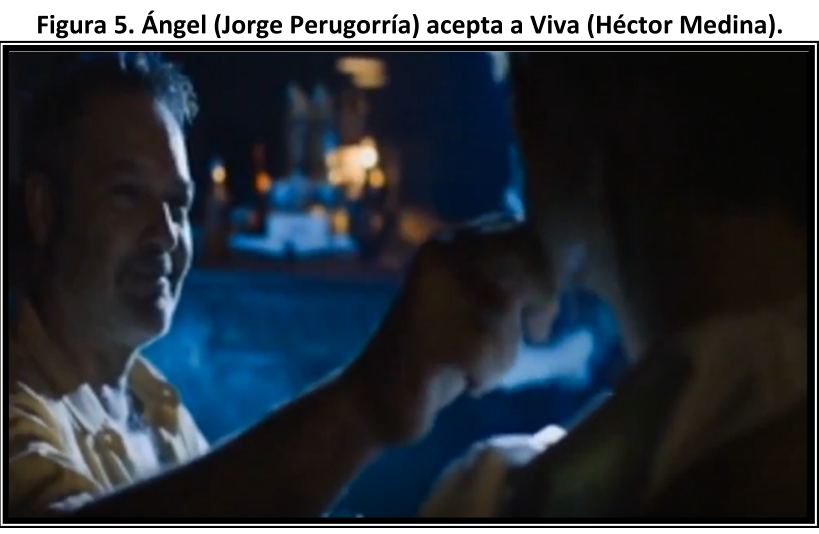

Fuente: Película Viva (2015)

A partir de este momento la película está cargada de un intenso pathos. Padre e hijo han logrado aceptarse recíprocamente. La vida les ha dado la posibilidad de conocerse y de despedirse. Su convivencia ha sido breve, complicada y sincera. En sus últimos minutos de vida el padre admite que Jesús es un buen muchacho y un buen artista. Le pide que se reciba a Cecilia en su casa, para que esta y el niño que está en su vientre se encuentren protegidos. La desesperación del joven ante la agonía de su progenitor demuestra que el amor entre ellos es fuerte. Ambos han logrado superar los prejuicios que habían hecho de un encuentro inicial un fracaso.

Ángel muere. Cecilia y Jesús están juntos durante los preparativos para el funeral. El protagonista siente un gran dolor que logra desahogarlo por medio de Viva. La película cierra combinando escenas de su última presentación, en la que interpreta El amor de Yolandita Monge con escenas de su vida en común con Cecilia. El texto de la canción describe las sensaciones que despierta el amor cuando nace y cuando se pierde. El llanto de Viva en el escenario nos da a entender que la canción está siendo dedicada a su padre. Esta es en absoluto su mejor representación. El público unánimemente la aplaude. Por medio del dolor que produce la ausencia de su padre, logra alcanzar esa intensidad que tanto buscaba desde que comenzó a trabajar en el cabaré. Adicionalmente, se convierte en el padre putativo del hijo del hijo de Cecilia y Javier ${ }^{11}$.

\section{Conclusiones}

Al comenzar este estudio, partí de la perspectiva de demostrar la función del cabaré como espacio heterotópico y en la importancia del encuentro Jesús/Ángel para que este pudiese devenir totalmente Viva. Después de haber llevado a cabo el análisis del barrio de Jesús, del ambiente del cabaré y de su encuentro con Ángel, se puede concluir que Viva es un filme comprometido que muestra la doble moral de una sociedad que tacha de débiles a los homosexuales, finge no percatarse de los ingresos económicos que genera la prostitución masculina y cierra los ojos ante la discriminación sexual. Aunque Jesús se dedica a actividades ilícitas para obtener dinero, su personaje difiere de los personajes masa de su barrio. Es sensible, generoso con lo poco que tiene, sentimental y nostálgico. Estas características predisponen su amor a la música y hacen que encuentre conforto en el ambiente artístico del cabaré. En la película el cabaré es presentado como un espacio heterotópico. Es el contra-lugar de la cotidianidad diurna de Jesús, el sitio donde puede explorar y asumir su feminidad sin ser juzgado. Mama, transexual que lidera el cabaré, es uno de los catalizadores para que Jesús pueda devenir Viva. Esta asume un papel de madre del protagonista

\footnotetext{
${ }^{11}$ No deja de ser extraña una cierta connotación crística entorno al personaje, pues Jesús, el hijo de Ángel, se convierte en el salvador del hijo de Javier, en el padre putativo del hijo del hombre nuevo cubano.
} 
dentro del espacio heterotópico. Gracias a ella y a las otras vedettes, Jesús entiende que Viva es parte de su multiplicidad.

El encuentro entre Jesús y Ángel tiene lugar después de que ambos han estado en espacios heterotópicos. Aunque padre e hijo son muy diversos. El machismo excesivo del primero y la homosexualidad del segundo convierte a ambos en desadaptados sociales. La parrhesía se convierte en un elemento importante para que Ángel y Jesús puedan conocerse y recuperar el tiempo perdido. Esta permitirá que ambos personajes se acepten como son. Sin embargo, será solamente con la muerte de su padre y por medio del dolor que produce su ausencia definitiva que Jesús logra alcanzar verdaderamente esa intensidad que tanto buscaba desde que comenzó a trabajar en el cabaré y que finalmente logra devenir totalmente Viva. 


\section{Bibliografía}

Aparicio, Y. \& Ángel E. (2017). En el cine cubano actual: de Tomás Gutiérrez Alea a Juan de los muertos. Poética de una desintegración. Literatura y cultura cubanas en tiempos de cambio. Editorial Verbum: Madrid: 127-143.

Deleuze, G. \& F. Guattari. (1978). Mil mesetas. Pre-textos. Valencia.

Deleuze, G. (1987). Qu'est-ce que l'acte de création?. Deux régimes de fous et autres, http://www.lepeuplequimanque.org/acte-de-creation-gilles-deleuze.html

Elsaesser, T. (1991). Tales of Sound and Fury: Observations on the Family Melodrama. Imitations of Life: A Reader on Film and Television Melodrama. Wayne State University Press: Detroit: 68-92.

Foucault, M. (2004). Des espaces autres. Empan 2 : 12-19.

Foucault, M. (2010). El coraje de la verdad. FCE, México.

Fusco, C. (1998). Hustling for dollars: jineterismo in Cuba. Global Sex Workers: Rights, Resistance, and Redefinition. Routledge: Nueva York: 151-166.

Butler, J. (2006). Deshacer el género. Paidós, Buenos Aires.

Portales, Y. S. (2009). Para que otra voz se escuche. Sobre el reconocimiento legal y social de las personas LGBT en Cuba en la primera década del siglo XXI. Enfoques: 1-24.

Sierra Madero, A. (2013). Cuerpos en venta: pinguerismo y masculinidad negociada en la Cuba contemporánea. Nómadas 38: 167-183.

Breathnach P. (2015). Viva. Treasure Entertainment. 